\title{
On the Genus Paragoniastes Comellini, 1979, with Description of a New Species from Ilhéus, Brazil (Coleoptera, Staphylinidae, Pselaphinae)
}

\author{
Giulio Cuccodoro, ${ }^{1}$ Sergey A. Kurbatov, ${ }^{2}$ Luciano Pereira de Oliveira, ${ }^{3}$ \\ and Mytalle Santana Fonseca ${ }^{3}$ \\ ${ }^{1}$ Department of Entomology, Muséum d'Histoire Naturelle, Case Postale 6434, 1211 Genève 6, Switzerland \\ ${ }^{2}$ Museum of Entomology, All-Russian Plant Quarantine Center, Pogranichnaya 32, Bykovo 140150, Russia \\ ${ }^{3}$ Laboratory of Entomology, Universidade Estadual de Santa Cruz, Rodovia Ilhéus/Itabuna km 16, Salobrinho, \\ 45662-000 Ilhéus, BA, Brazil
}

Correspondence should be addressed to Giulio Cuccodoro, giulio.cuccodoro@ville-ge.ch

Received 29 September 2011; Accepted 4 January 2012

Academic Editor: Howard Ginsberg

Copyright ( 2012 Giulio Cuccodoro et al. This is an open access article distributed under the Creative Commons Attribution License, which permits unrestricted use, distribution, and reproduction in any medium, provided the original work is properly cited.

The types of the species of the Goniacerine genus of Pselaphinae Paragoniastes Comellini are revised. Paragoniastes parki Comellini, 1979, is synonymized with P. besucheti Comellini, 1979 (P. besucheti = P. parki syn. nov.), and P. uesci Cuccodoro \& Kurbatov sp. nov. is described from the Brazilian state of Bahia. These taxa are described, illustrated, and keyed. Additional characters pertaining to the genus are given.

\section{Introduction}

Members of Paragoniastes are small predaceous rove beetles of the pselaphine tribe Goniacerini inhabiting the forest leaf litter. The genus was erected by Comellini to accommodate Goniastes westwoodi Raffray, 1890 from "Brésil" and three new species from the southern Brazilian states of Santa Catarina and Parana (P. besucheti, P. parki, and P. raffrayi).

In the frame of a survey of the pselaphine fauna of the Brazilian state of Bahia, we collected several Paragoniastes at the campus of Universidade Estadual de Santa Cruz, Ilhéus. Comparison of these specimens with the types of Paragoniastes housed in the Muséum d'histoire naturelle, Geneva, indicated not only that they were a new species but also that the holotype and unique specimen of $P$. parki is conspecific with the types of $P$. besucheti. The new species $(P$. uesci) is the first record of the genus in the Brazilian Nordeste.

The species are described and keyed, and their habitus is figured. We present drawings of the aedeagi of all the species of Paragoniastes, including that of $P$. westwoodi. We also mention some additional features pertaining to the genus, such as the system of meso- and metasternal foveae, and the conformation of the second visible abdominal sternite.

\section{Material and Methods}

All the specimens mentioned in this study (167 specimens) have been examined. These are housed in the Muséum d'histoire naturelle (MHNG), Geneva, Switzerland, in the Muséum National d'Histoire Naturelle (MNHN), Paris, France, and in the Universidade Estadual de Santa Cruz (UESC), Ilhéus, Brazil. In the future, the material deposited in UESC will be deposited in the Museu de Zoologia da Universidade de São Paulo (MZSP), Brazil.

The label data of the type of $P$. westwoodi are reproduced literally between " ", with additional information pertaining to labels, or localities between [ ], with | as a separator between each individual label.

Measurements are defined as follows: body length is measured from anterior outline of head (i.e., apical margin of labrum) to apex of abdomen; head width (HW) is the distance between outer outline of head just behind eyes; 
head length (HL) is the medial distance between tip of frontoclypeus and occipital margin; pronotal length (PL) is the medial distance between anterior and posterior margins of pronotum; pronotal width (PW) is the maximal distance between lateral outline of pronotum; elytral length $(\mathrm{EL})=$ elytral sutural length; elytral width (EW) is the maximal width of the elytra taken together. Antennal articles are measured in dorsal view, their length axially (without basal stalk), and their width at their maximal width.

The abdominal tergites and sternites are numbered according to Chandler [3] in Arabic (visible position) and Roman (morphological position) numerals; they are counted from tergite 1 (IV) and sternite 1 (III). Terminology of surface sculpturing follows Harris [4]. The aedeagi and other body parts illustrated here were mounted in Canada balsam on acetate slides and drawn using a drawing tube mounted on a compound microscope. The habitus figures are composites taken using a digital camera mounted onto a Leica MZ Apo dissecting microscope and processed using Automontage software.

\section{Taxonomy}

Key to the species of Paragoniastes

(1) (a) Center of pronotum areolate $-P$. besucheti Comellini.

(b) Center of pronotum covered with longitudinal ridges slightly diverging anteriorly-2.

(2) (a) Elytra smooth, without marked discal striaeP. westwoodi Raffray.

(b) Elytra scabriculate, with marked discal striae3.

(3) (a) Elytra lacking humeral stria. Mesofemora bearing posteriorly a conspicuous subbasal toothlike process-P. raffrayi Comellini.

(b) Elytra with humeral stria. Mesofemora bearing posteriorly at most an obsolete subbasal toothlike process-P. uesci sp. Nov.

\subsection{Paragoniastes Comellini, 1979.}

Paragoniastes Comellini, 1979: 681; type species: Paragoniastes raffrayi Comellini (by original designation).

Additional Characters. Habitus as in Figures 1(a), 1(b), 1(c), 1(d), 2(a), and 2(b). Maxillary palpi as in Figure 3(e). Pronotum with shallow medial antebasal fovea and pair of well-marked lateral antebasal depressions (without true lateral antebasal foveae). Elytron with sutural and lateral striae on entire elytral length; usually present is internal discal stria and external discal stria, and occasionally humeral stria; when present, discal and humeral striae evanescent subapically, internal discal and humeral striae reaching basal margin, and external stria evanescent subbasally. Prosternum with pair of lateral procoxal foveae; medial carina absent. Mesosternum (Figure 3(b)) scabriculate, except prepectus smooth; the latter larger than mesosternal shield, medially carinate and laterally concave to allow accommodation of procoxae; pair of lateral foveae in connection with pair of promesocoxal foveae. Mesocoxal cavities separated. Metasternum (Figure 3(b)) scabriculate, markedly delimited from mesosternum; with pair of lateral mesocoxal foveae and medial metasternal fovea. Legs with second tarsomeres slightly shorter than third; single tarsal claw. Abdominal tergites each 1-5 bearing four macrosetae, tergites $1-3$ each with medial ridge. Abdominal sternite 1 (Figure 3(d)) very short, visible only on mesal portion; sternite 2 (Figure 3(d)) bearing pair of deep transverse cavities densely covered by pubescence, each with basolateral and mediobasal foveae. Aedeagus with basal bulb of median lobe membranous and two symmetrical parameres.

Comments. Particularly notable in the genus is the structure of the lateral and promesocoxal foveae, which are unusually connected with each other, suggesting that the promesocoxal foveae might result from an extreme bifurcation of the lateral foveae. The membranous basal bulb of the aedeagus can easily collapse and its shape is thus not discriminant. Sexual dimorphism appears to affect only the medial area of the abdominal sternites. The presence of mesofemoral spines in both sexes is particularly notable, as it is usually a sexually dimorphic feature in Pselaphinae.

3.1.1. Paragoniastes raffrayi Comellini, 1979. See Figures 1(a), $1(\mathrm{~b})$, and 3.

\section{Paragoniastes raffrayi Comellini, 1979: 682.}

Material examined (holotype and 156 paratypes, all in MHNG): "Brésil, Santa Catarina, Nova Teutonia, F. Plaumann, vi.1972", 1 macrophthalmus male (holotype), 13 microphthalmus males and 12 females; same data, but xii.1967, 3 microphthalmus males and 1 female; same data, but xii.1969, 1 female; same data, but i.1970, 2 females; same data, but ii.1970, 1 macrophthalmus male and 2 females; same data, but v.1970, 1 macrophthalmus male; same data, but iii.1972, 1 female; same data, but x.1972, 1 macrophthalmus male, 2 microphthalmus males and 2 females; same data, but xii.1972, 2 females; same data, but ii.1973, 1 macrophthalmus male and 1 female; same data, but xi.1974, 2 macrophthalmus males and 5 females; same data, but iv.1976, 21 macrophthalmus males, 34 microphthalmus males and 48 females.

Description. Body (Figures 1(a) and 1(b)) $1.75-1.80 \mathrm{~mm}$ long. Head 1.2-1.3 times longer that wide (without eyes). Antennae (holotype) with scape 1.1-1.2 times longer than pronotal width; 2 nd article somewhat transverse; 3 rd 1.7-1.8 times longer than wide, 2.6-2.8 times longer than 2 nd and 1.4-1.5 times longer than 4th; 4th 1.1-1.2 times longer than wide; 5th 1.6 times longer than wide and about as long as 3 rd. Pronotum as long as wide, covered with longitudinal ridges slightly diverging anteriorly, except posterior quarter scabriculate. Elytra scabriculate, without transverse carinulae. Elytral internal and external discal striae well marked; humeral stria absent, or at most obsolete on basal quarter. 


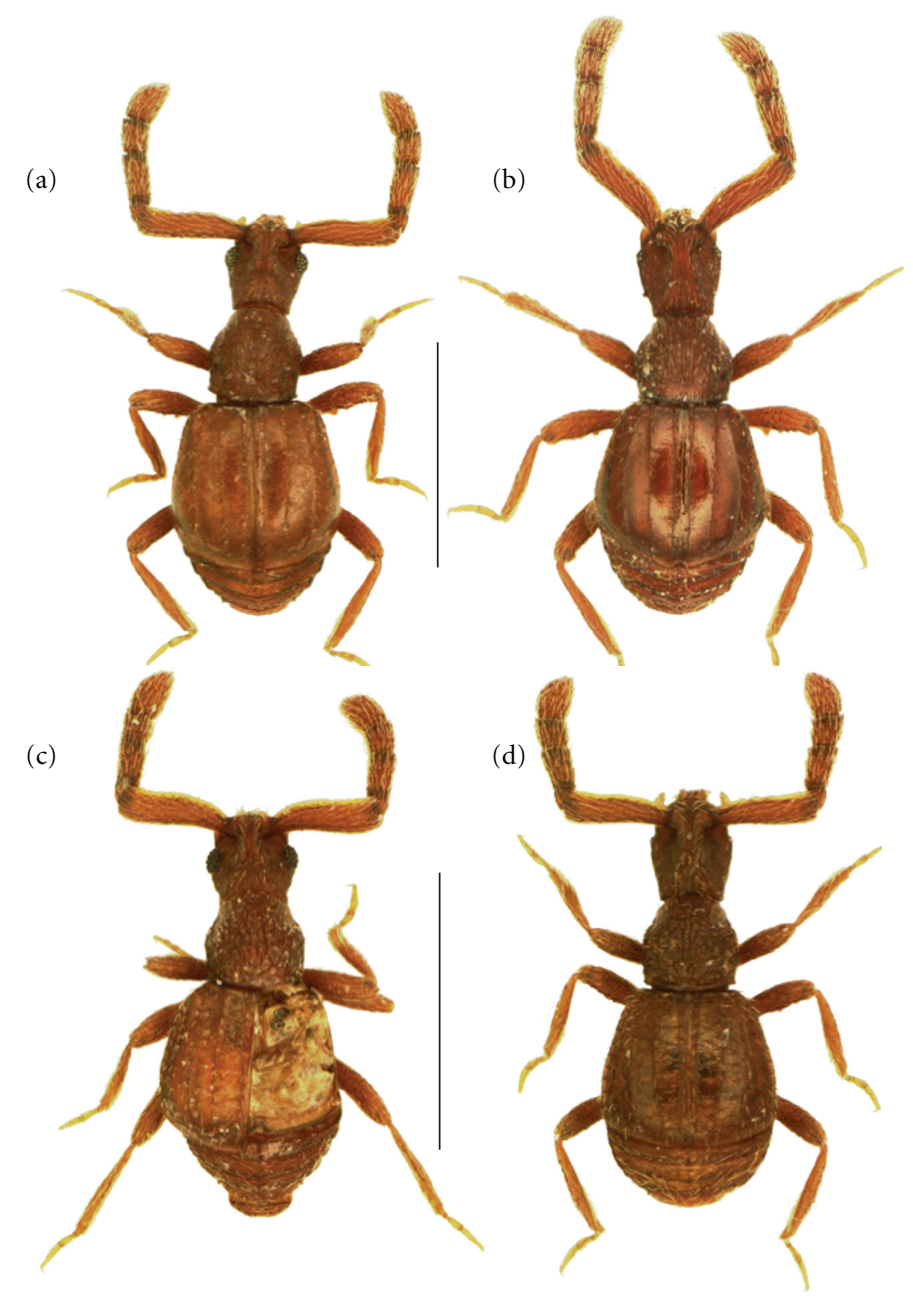

Figure 1: (a) and (b) Paragoniastes raffrayi, male, macrophthalmus (a) and microphthalmus (b). (c) and (d): P. besucheti, male, macrophthalmus ((c): holotype of P. parki) and microphthalmus ((d): holotype). Scale bars: $1 \mathrm{~mm}$.

Presence of 13 setae arranged along internal discal striae; strial setae about as long as interval between them, and more than three times longer that interstrial setae, the latter almost indistinct. Mesofemora bearing posteriorly a conspicuous subbasal tooth-like process.

Measurements (holotype): $\mathrm{HL}=0.43 \mathrm{~mm} ; \mathrm{HW}=0.34$ $\mathrm{mm} ; \mathrm{PL}=0.40 \mathrm{~mm} ; \mathrm{PW}=0.40 \mathrm{~mm} ; \mathrm{EL}=0.71 \mathrm{~mm} ; \mathrm{EW}=$ $0.75 \mathrm{~mm}$.

(i) Male. Eyes of macrophthalmus individuals with 28-30 facets, microphthalmus individuals with 5-8 facets. Abdominal sternites 2-5 medially depressed. Aedeagus (Figures 3(a) and 3(c)) 0.20-0.21 mm long.

(ii) Female. Eyes with 5 facets.

Distribution. Paragoniastes raffrayi is apparently restricted to the south Brazilian state of Santa Catarina, where it occurs in sympatry with $P$. besucheti.

Comments. Within the specimens examined, the sex ratio is $50 \%$, and $35 \%$ of the males are macrophthalmus. Paragoniastes raffrayi is easily distinguished from its congeners by the presence of marked discal striae in combination with the almost completely evanescent humeral stria. The presence of mesofemoral spines in both sexes is particularly notable, as it is usually a sexually dimorphic feature in Pselaphinae.

3.1.2. Paragoniastes besucheti Comellini, 1979. See Figures 1(c), 1(d), 4(a)-4(d).

Paragoniastes besucheti Comellini, 1979: 686.

Paragoniastes parki Comellini, 1979: 685 syn. nov.

Material examined (6 specimens, all in MHNG): "Brésil, Santa Catarina, Nova Teutonia, F. Plaumann, xii.1976”, 1 microphthalmus male (holotype of $P$. besucheti); same data, but xi.1976, 1 macrophthalmus male (holotype of $P$. parki) and 1 microphthalmus male (paratype of $P$. besucheti); “Brésil, [Parana], Rondon, $<24^{\circ} 38^{\prime} \mathrm{S} ; 54^{\circ} 07^{\prime} \mathrm{E}>$ F. Plaumann, iii.1965" 2 microphthalmus males and 1 female (paratypes of P. besucheti).

Description. Body (Figures 1(c) and 1(d)) 1.45-1.50 mm long. Head 1.2-1.3 times longer than wide (without eyes). 

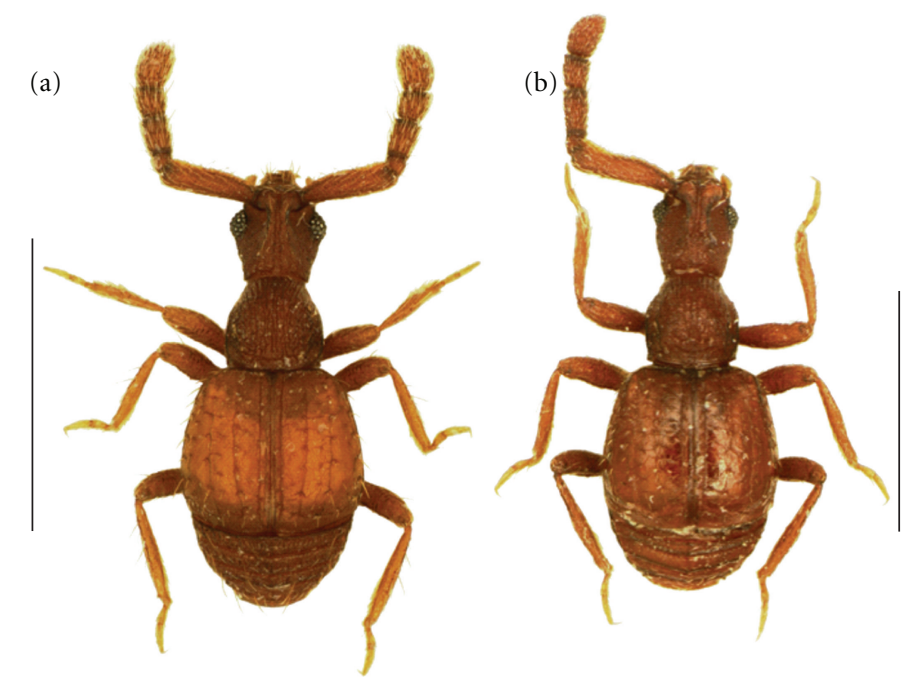

Figure 2: (a) Paragoniastes uesci, male, macrophthalmus (paratype). (b) P. westwoodi, male, macrophthalmus (holotype). Scale bars: 1 mm.

Antennae (holotype) with scape 1.1-1.2 times longer than pronotal width; 2 nd article as long as wide; 3 rd 1.6-1.7 times longer than wide, 1.8-1.9 times longer than 2nd and 1.31.4 times longer than 4th; 4 th somewhat longer than wide; 5th 1.6-1.7 times longer than wide and 1.2-1.3 times longer than 3rd. Pronotum slightly wider than long, areolate, except anterior quarter covered with longitudinal ridges slightly diverging anteriorly. Elytra smooth, irregularly covered with transverse carinulae. Elytral internal and external discal striae well-marked; humeral stria present on more that three quarters of elytral length. Presence of 13 setae arranged along internal discal striae; strial setae about as long as interval between them, and about as long as interstrial setae. Mesofemora bearing posteriorly at most obsolete subbasal toothlike process.

Measurements (holotype): $\mathrm{HL}=0.37 \mathrm{~mm} ; \mathrm{HW}=0.30$ $\mathrm{mm} ; \mathrm{PL}=0.32 \mathrm{~mm} ; \mathrm{PW}=0.34 \mathrm{~mm} ; \mathrm{EL}=0.54 \mathrm{~mm} ; \mathrm{EW}=$ $0.60 \mathrm{~mm}$.

(i) Male. Eyes of macrophthalmus individuals with 34 facets, microphthalmus individuals with 3-5 facets. Abdominal sternites 2-4 medially depressed, 2-3 each with spinose medial process consisting of few agglomerated setae projecting from small medial tubercle, these tubercles not contiguous. Aedeagus (Figures 4(a), 4(b), 4(c) and 4(d)) 0.27-0.28 mm long.

(ii) Female. Eyes with 4-5 facets.

Distribution. Paragoniastes besucheti occurs in the south Brazilian states of Santa Catarina (in sympatry with P. raffrayi) and Paraná.

Comments. This species is the only member of the genus to possess an areolate pronotum. Close examination of the holotypes $P$. besucheti and $P$. parki indicated that the apparent differences between Comellini's aedeagal drawings of these two species result from misinterpretation of details and deformations of these structures on the microscope slides where the aedeagi were mounted.

\subsubsection{Paragoniastes uesci Cuccodoro \& Kurbatov sp. nov.} See Figures 2(a), 4(e), and 4(f).

Holotype (macrophthalmus male, in UESC): "Brazil, Bahia, Ilhéus, Universidade Estadual de Santa Cruz (UESC), $80 \mathrm{~m}<14^{\circ} 39^{\prime} \mathrm{S}, 39^{\circ} 10^{\prime} \mathrm{W}>\mathrm{L}$. Pereira de Oliveira, M. Santana Fonseca \& G. Cuccodoro, 31.vii.2011, sifting leaf litter in the forest of the campus".

Paratypes (2): same data as holotype, 1 macrophthalmus male in MHNG and 1 female in UESC.

Description. Body (Figure 2(a)) 1.50 mm long. Head 1.2-1.3 times longer than wide (without eyes). Antennae (holotype) with scape as long as pronotal width; 2nd article as long as wide; 3 rd 1.4-1.5 times longer than wide, 1.9-2.0 times longer than 2nd and 1.3-1.4 times longer than 4th; 4th as long as wide; 5th 1.3-1.4 times longer than wide and 1.2-1.3 times longer than 3rd. Pronotum slightly wider than long, entirely covered with longitudinal ridges slightly diverging anteriorly. Elytra scabriculate, irregularly covered with transverse carinulae. Elytral internal and external discal striae well-marked; humeral stria present on more that three quarters of elytral length. Presence of 10 setae arranged along internal discal striae; strial setae about as long as interval between them, and about two times longer than interstrial setae. Mesofemora bearing posteriorly at most an obsolete subbasal tooth-like process.

Measurements (holotype): $\mathrm{HL}=0.36 \mathrm{~mm} ; \mathrm{HW}=0.29$ $\mathrm{mm} ; \mathrm{PL}=0.32 \mathrm{~mm} ; \mathrm{PW}=0.34 \mathrm{~mm} ; \mathrm{EL}=0.57 \mathrm{~mm} ; \mathrm{EW}=$ $0.62 \mathrm{~mm}$.

(i) Male. Eyes of macrophthalmus individuals with 3032 facets (microphthalmus individuals unknown). Abdominal sternite 2 with small medioapical tubercle bearing short setae directed forward; sternites 3-5 

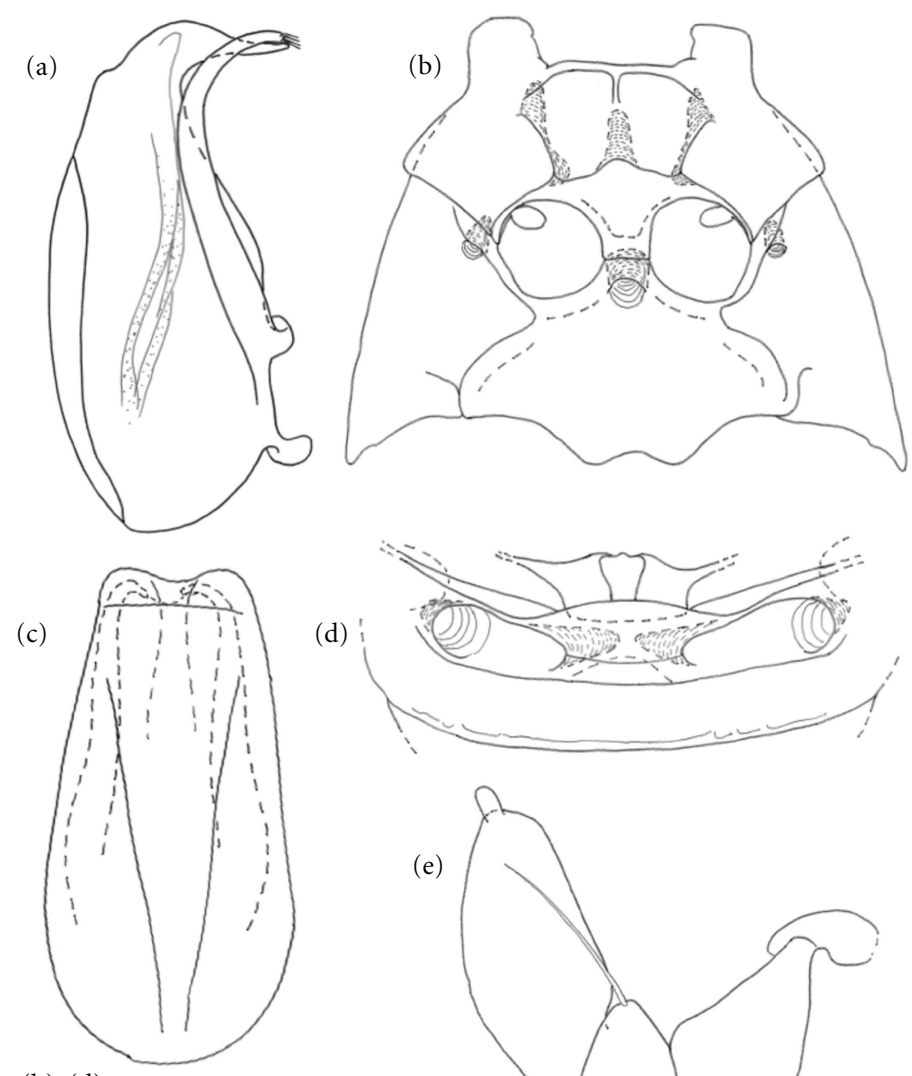

(d)

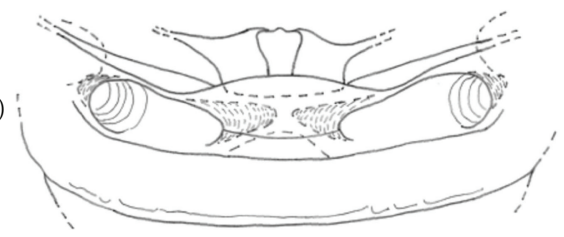

(b), (d)

(a), (c)

(e)

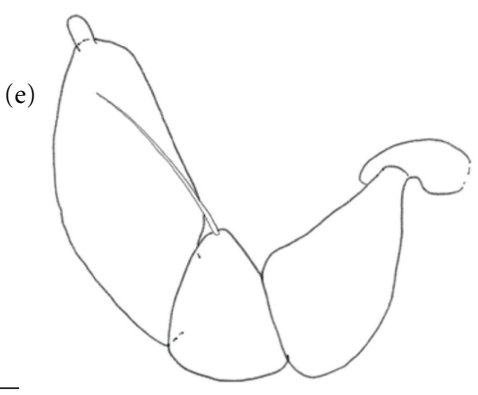

Figure 3: Paragoniastes raffrayi. (a) and (c): Aedeagus in lateral (a) and dorsal (c) views. (b) Mesosternum and metasternum, female, ventral view, pubescence omitted. (d): Medial area of abdominal sternites 1-2, female, ventral view, pubescence omitted. (e) Left maxillary palpus, female, dorsal view. Scale bars: $0.1 \mathrm{~mm}$.

medially depressed. Aedeagus (Figures $4(\mathrm{e})$ and $4(\mathrm{f})$ ) $0.25-0.26 \mathrm{~mm}$ long.

(ii) Female. Eyes with 1 facet.

Distribution. This species is known so far only from the state of Bahia and represents the first record of the genus in the Brazilian Nordeste.

Comments. Paragoniastes uesci is the only member of the genus with the pronotum entirely covered with longitudinal ridges slightly diverging anteriorly in combination with long and well-marked elytral humeral striae.

Etymology. The epithet uesci is an acronym for the Universidade Estadual de Santa Cruz, Ilhéus, campus where the new species was discovered.

3.1.4. Paragoniastes westwoodi (Raffray, 1890). See Figures 2(b), 4(g), and 4(h).

Goniastes westwoodi Raffray, 1890: 209.

Material examined (holotype, macrophthalmus male, in MNHN): "Brésil [handwritten on white rectangular label] | Muséum Paris, 1917/col. A. Raffray [typewritten on green rectangular label] | Type [typewritten on red rectangular label] | G. westwoodi [handwritten]/A. Raffray det. [typewritten on white rectangular label] | Goniastes westw [handwritten on green rectangular label] | Goniastes westwoodi Raffray type | Paragoniastes westwoodi (Raffray) type [handwritten on white rectangular label]".

Description. Body (Figure 2(b)) $1.80 \mathrm{~mm}$ long. Head 1.4-1.5 times longer than wide (without eyes). Antennae (holotype) with scape 1.1-1.2 times longer than pronotal width; 2nd article as long as wide; 3 rd 1.7-1.8 times longer than wide, 1.9-2.0 times longer than 2nd and 1.4-1.5 times longer than 4th; 4th 1.1-1.2 times longer than wide; 5th 1.5-1.6 times longer than wide and 1.1-1.2 times as long as 3rd. Pronotum as long as wide, covered with longitudinal ridges slightly diverging anteriorly, except posterior quarter scabriculate. Elytra smooth, irregularly covered with transverse carinulae. Elytral internal and external discal striae evanescent; humeral stria absent, or at most obsolete on basal quarter. Presence of 13 setae arranged along internal discal striae; strial setae about as long as interval between them, and about as long as interstrial setae. Mesofemora bearing posteriorly at most an obsolete subbasal tooth-like process. 

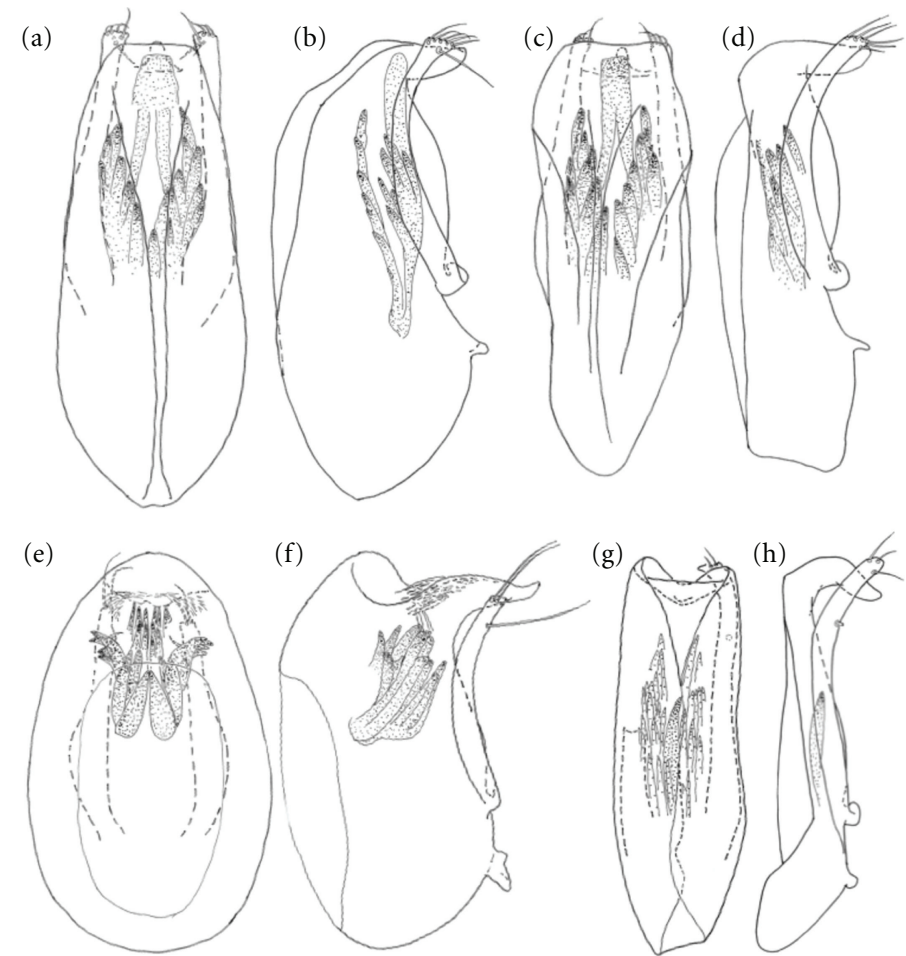

(a)-(f)

(g)-(h)

Figure 4: (a-b) Paragoniastes besucheti ((a) and (b) holotype; (c) and (d) holotype of P. parki). (e) and (f) P. uesci (holotype). (g) and (h) P. westwoodi (holotype, feft paramere broken). Aedeagus in dorsal (a, c, e, and g) and lateral (b, d, f, and h) views. Scale bars: $0.1 \mathrm{~mm}$.

Measurements (holotype): $\mathrm{HL}=0.49 \mathrm{~mm} ; \mathrm{HW}=0.34$ $\mathrm{mm} ; \mathrm{PL}=0.41 \mathrm{~mm} ; \mathrm{PW}=0.41 \mathrm{~mm} ; \mathrm{EL}=0.72 \mathrm{~mm} ; \mathrm{EW}=$ $0.77 \mathrm{~mm}$.

(i) Male. Eyes of macrophthalmus individual with 34 facets (microphthalmus individuals unknown). Abdominal sternites 2-3 not depressed, each with small medial tubercle bearing short setae directed backward, these tubercles contiguous; sternite 4 medially depressed. Aedeagus (Figures 4(g) and 4(h)) $0.35 \mathrm{~mm}$ long.

(ii) Female. Unknown.

Distribution. The only information available on the distribution of this species is that it comes from Brazil.

Comments. Paragoniastes westwoodi is the only member of the genus with evanescent discal striae.

\section{Acknowledgments}

The authors thank A. Taghavian (Paris) for arranging the loan of the type of Goniastes westwoodi Raffray housed in MNHN. This research was partly supported by a grant of the "Programa de Pós-Graduação em Zoologia" at UESC awarded to L. Pereira de Oliveira (FAPESB/1259/2011).

\section{References}

[1] A. Comellini, "Notes sur les Psélaphides néotropicaux (Coleoptera). 1, Deux nouveaux genres de la tribu des Goniacerini," Revue Suisse de Zoologie, vol. 86, no. 3, pp. 681-689, 1979.

[2] A. Raffray, "Études sur les Psélaphides (suite). VI. Diagnoses des espèces nouvelles sur lesquelles sont fondés des genres nouveaux," Revue d'Entomologie, vol. 9, pp. 193-219, 1890.

[3] D. S. Chandler, Biology, Morphology, and Systematics of the AntLike Litter Beetle Genera of Australia (Coleoptera: Staphylinidae: Pselaphinae), vol. 15 of Memoirs on Entomology, International, 2001.

[4] R. A. Harris, "A glossary of surface sculpturing," Occasional Papers in Entomology, vol. 28, pp. 1-31, 1979. 

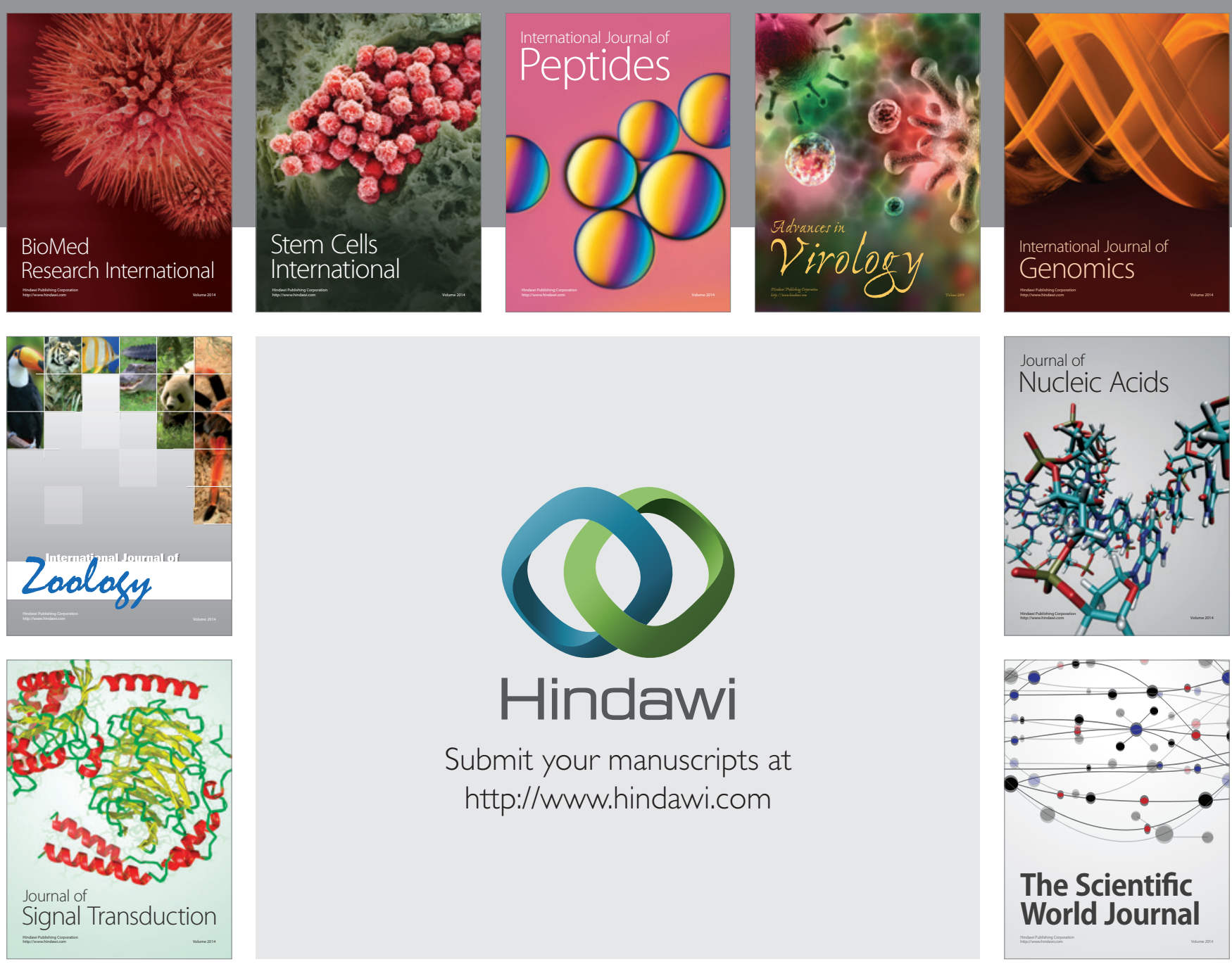

Submit your manuscripts at

http://www.hindawi.com
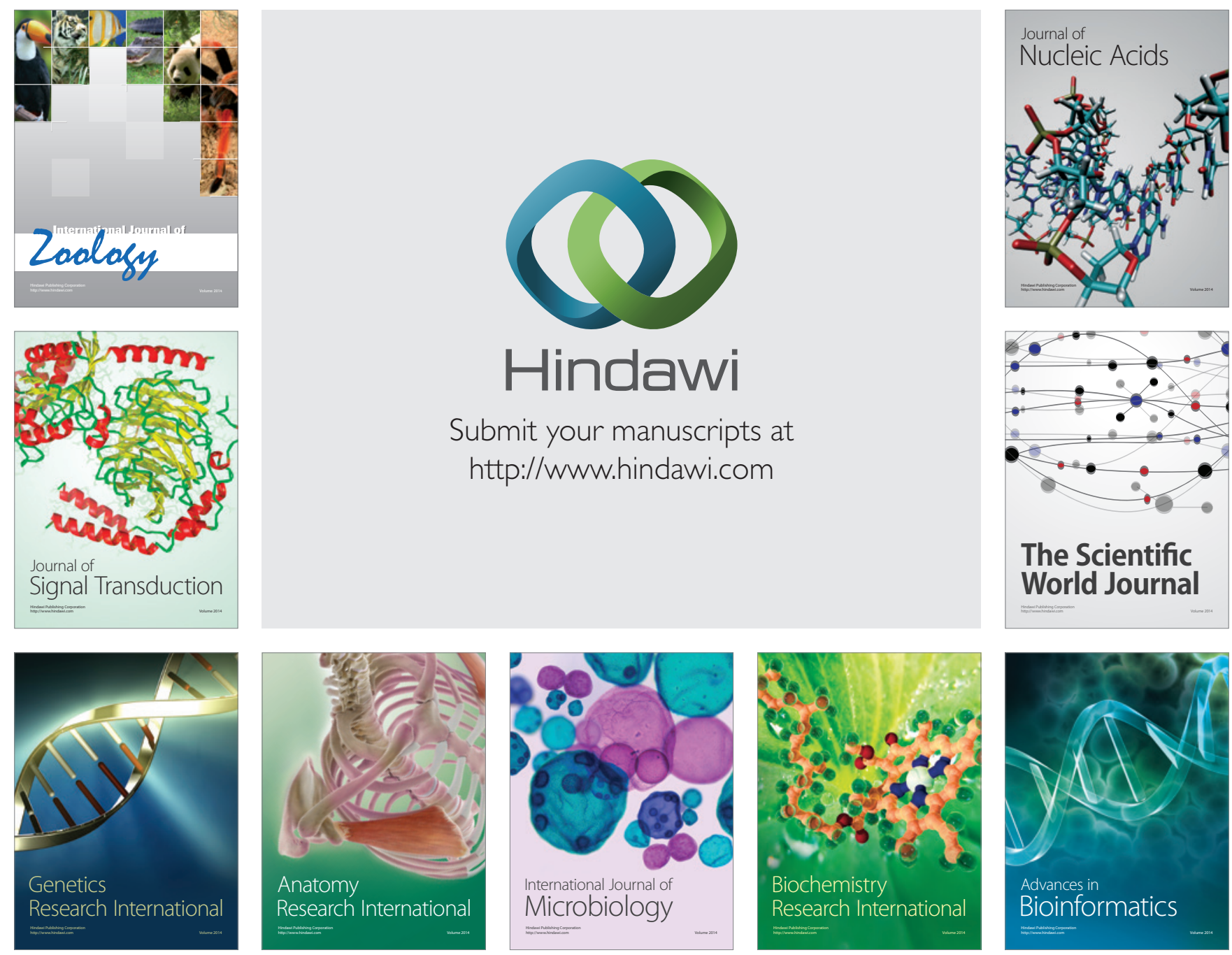

The Scientific World Journal
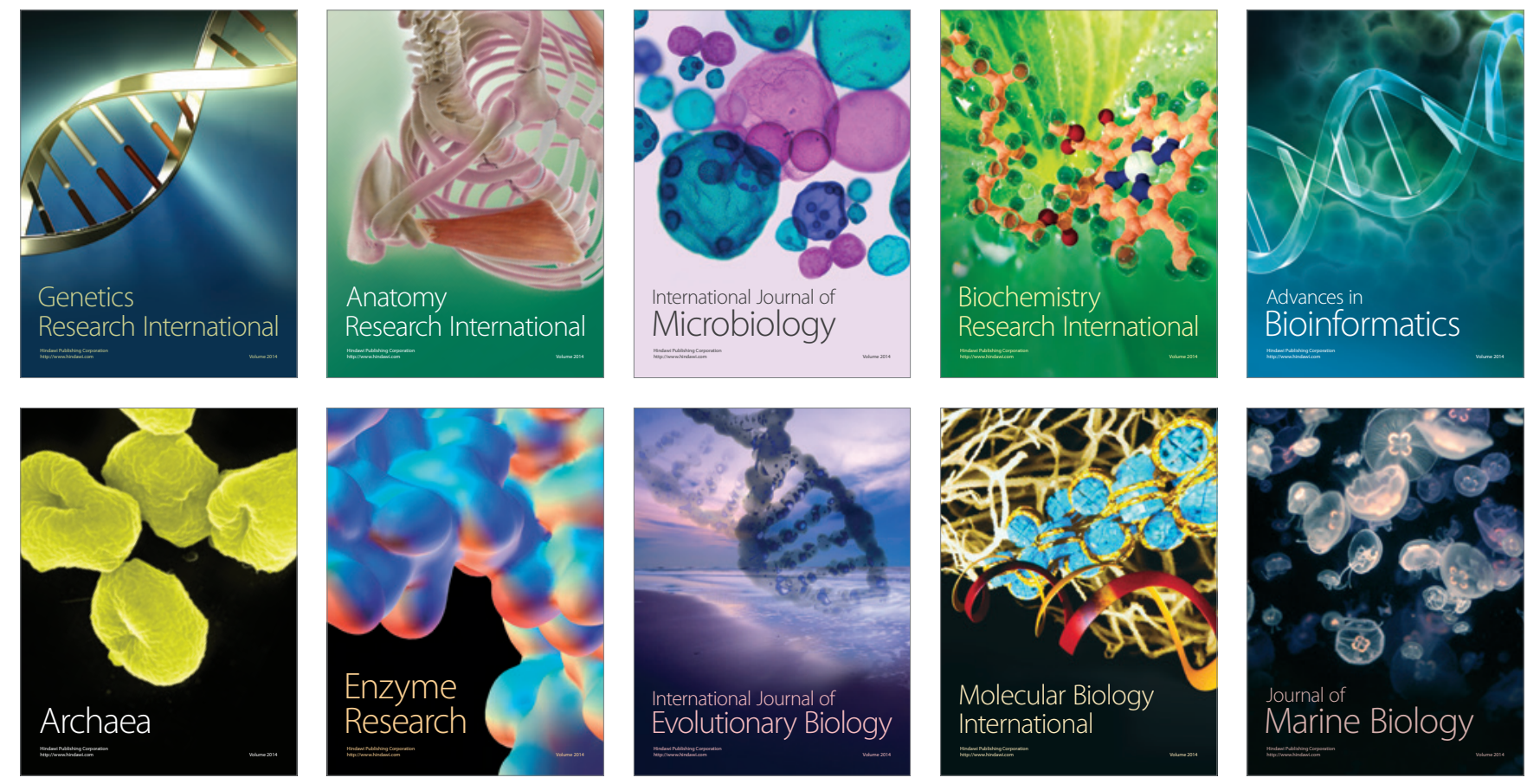